\title{
Heat-induced Leaf Senescence and Hormonal Changes for Thermal Bentgrass and Turf-type Bentgrass Species Differing in Heat Tolerance
}

\author{
Yan Xu and Bingru Huang ${ }^{1}$ \\ Department of Plant Biology and Pathology, Rutgers University, 59 Dudley Road, New Brunswick, \\ New Jersey 08901
}

\begin{abstract}
AdDitional INDEX wORDs. heat stress, senescence-related hormone, ethylene, abscisic acid, cytokinin, heat-tolerant heat-sensitive

Abstract. Leaf senescence can be induced by many environmental stresses, including supraoptimal temperatures. The objectives of this study were to evaluate leaf senescence induced by heat stress for two Agrostis species contrasting in heat tolerance and to examine whether heat-induced leaf senescence in both species was associated with changes in three major senescence-related hormones: ethylene, abscisic acid (ABA), and cytokinins. Plants of heat-tolerant rough bentgrass (Agrostis scabra Willd.) and heat-sensitive creeping bentgrass (Agrostis stolonifera L.) were exposed to $35 / 30{ }^{\circ} \mathrm{C}$ (day/night) (high temperature) or $20 / 15{ }^{\circ} \mathrm{C}$ (control) for $35 \mathrm{~d}$ in growth chambers. Turf quality, photochemical efficiency ( $\mathrm{Fv} / \mathrm{Fm})$, and the contents of two pigments (chlorophyll and carotenoid) for both species decreased under high temperature; however, heat-tolerant $A$. scabra exhibited delayed and less severe decline in all parameters compared with heat-sensitive $A$. stolonifera. Ethylene production rate increased in both species at $35^{\circ} \mathrm{C}$, but the increase was observed 21 days later in $A$. scabra compared with that in $A$. stolonifera. ABA content increased at the initiation of heat stress and then declined in both species after prolonged heat stress. However, the timing of the increase was delayed for 7 days and the highest level of ABA content was less in A. scabra (4.0 times that of the control) than that in $A$. stolonifera (5.9 times that of the control). Decreases in both forms of cytokinins (transzeatin/zeatin riboside and isopentenyl adenosine) were also delayed for 14 days and less pronounced in $A$. scabra. Correlation analysis revealed that leaf senescence induced by heat stress was negatively correlated to ethylene and $\mathrm{ABA}$ accumulation and positively correlated to cytokinin production. Delayed leaf senescence in $A$. scabra under heat stress could be related to slower and less magnitude of changes in ethylene, ABA, and cytokinins.
\end{abstract}

High temperature is a major factor limiting growth of coolseason plant species. One of the typical symptoms of heat injury for many plant species is leaf senescence (Thomas and Stoddart, 1980). Leaf senescence is characterized by loss of chlorophyll and photosynthetic activities in leaves (John et al., 1995). Heat-induced leaf senescence and associated changes in physiological activities have been reported in various plant species (Thomas and Stoddart, 1980; Xu et al., 1995; Yeh and Hsu, 2004). Xu et al. (1995) reported that increases in temperature during maturation of wheat (Triticum aestivum L.) enhanced leaf senescence, accentuated the loss of chloroplast integrity, and accelerated the decline of PSII-mediated electron transport. Cool-season turfgrass species such as Agrostis stolonifera are sensitive to heat stress and experience a series of physiological injuries when exposed to temperatures above $30^{\circ} \mathrm{C}$. Leaf senescence was observed after $20 \mathrm{~d}$ at $30{ }^{\circ} \mathrm{C}$ and only $8 \mathrm{~d}$ at $35^{\circ} \mathrm{C}$ for $A$. stolonifera cv. Penncross (Huang and Gao, 2000; Huang et al., 1998).

Many physiological and biochemical factors such as plant hormone levels can be related to leaf senescence. In many nonturf plant species, it has been found that both genetically and environmentally regulated senescence are associated with hormonal changes with either upregulating or downregulating

Received for publication 6 Apr. 2006. Accepted for publication 28 Sept. 2006. We thank Rutgers Center for Turfgrass Science for funding and Dr. H. Frenkel for his help with GC. Thanks also go to Dr. Shimon Rachmilevitch, Dr. Michelle Dacosta, Steve McCann, and Emily Merewitz for critical review of the manuscript.

${ }^{1}$ Corresponding author. E-mail: huang@aesop.rutgers.edu. effects (Nooden and Leopoid, 1988). Ethylene, abscisic acid (ABA), and cytokinins are three major phytohormones that mediate signaling events involved in plant senescence (Chang et al., 2003). It has been reported that exogenous ethylene can accelerate processes characteristic of leaf senescence such as the decline of chlorophyll and increases in activity of hydrolytic enzymes (Grbic and Bleecker, 1995). In addition, delayed leaf senescence was observed in transgenic ethylene-deficient tomato (Lycopersicon esculentum Mill. cv. Ailsa Craig) plants (John et al., 1995). ABA is involved in many plant responses to biotic and abiotic stresses. Rapid ABA accumulation has been observed when plants are subjected to drought, salinity, and extreme temperatures (Xiong et al., 2002). Some studies also found that ABA accumulation may induce leaf senescence. Spraying ABA reduced leaf chlorophyll content in rice (Oryza sativa L.) (Yang et al., 2002). Becker and Apel (1993) reported that senescence-associated mRNAs were induced by ABA in detached leaves of barley (Hordeum vulgare L.). In contrast to the actions of ethylene and ABA, cytokinins retard senescence in vegetative and floral tissues (Nooden and Leopoid, 1988). In transgenic $\mathrm{P}_{\mathrm{SAG} 12}$-IPT tobacco (Nicotiana tabacum L.) plants, enhancement in cytokinin synthesis significantly delayed leaf senescence, reduced damage to chlorophyll and the photosynthetic system and nitrogen translocation to nonsenescing leaves (Jordi et al., 2000). Applying benzyladenine, a synthetic substance that is similar to cytokinin in structure and function, to the leaves of bean (Phaseolus vulgaris L.) plants helped maintain high chlorophyll content, thus delaying leaf senescence under normal environmental conditions (Adedipe, 1971). 
The mechanisms of heat-induced leaf senescence in turfgrass species are largely unknown despite extensive research in other plant species as discussed previously. Identification of physiological or metabolic factors associated with senescence has practical value for turfgrass management and is important for revealing basic mechanisms of plant heat tolerance. Recently, a heat-tolerant $\mathrm{C}_{3}$ perennial grass species, Agrostis scabra, has been identified growing in geothermally heated areas in Yellowstone National Park, Wyo. (Stout and Al-Niemi, 2002). It survives or even thrives in the chronically hot soils with temperatures up to $45{ }^{\circ} \mathrm{C}$ (Tercek et al., 2003). When exposed to $35^{\circ} \mathrm{C}$ in controlled-environment chambers, these plants maintain green leaves longer than A. stolonifera, a widely cultivated cool-season grass whose optimal growth temperature is between 10 and $18^{\circ} \mathrm{C}$. Our objectives were to evaluate leaf senescence induced by heat stress for these two Agrostis species contrasting in heat tolerance and to determine whether heat-induced leaf senescence in both Agrostis species was associated with changes in the three major senescencerelated hormones (ethylene, ABA, and cytokinins). Turf quality, photochemical efficiency, and the content of two pigments (chlorophyll and carotenoid) were measured to evaluate the degree of heat tolerance and leaf senescence. Quantitative changes in ethylene, ABA, and two major forms of cytokinins, transzeatin/zeatin riboside (Z/ZR) and isopentenyl adenosine (iPA), during heat stress were determined to examine their relationship with heat-induced leaf senescence.

\section{Materials and Methods}

Plant materials. Agrostis stolonifera cv. Penncross plugs were collected from field plots at Hort Farm II, Rutgers University, New Brunswick, N.J. Plants of A. scabra, originally collected from geothermally heated areas in Yellowstone National Park, Wyo., were propagated in a greenhouse at Rutgers University. Both species were planted in 24 welldrained plastic pots ( $15 \mathrm{~cm}$ diameter and $20 \mathrm{~cm}$ deep) filled with sterilized sand and fertilized weekly with $100 \mathrm{~mL}$ full-strength Hoagland's solution. Plants were cut weekly to maintain a canopy height of $\approx 5 \mathrm{~cm}$. After 1 month of establishment in the greenhouse, plants were transferred into controlled-environment growth chambers (Conviron, Winnipeg, Canada) with a temperature of $20 / 15{ }^{\circ} \mathrm{C}$ (day/night), 14-h photoperiod, $50 \%$ average relative humidity, and $400 \mu \mathrm{mol} \cdot \mathrm{m}^{-2} \cdot \mathrm{s}^{-1}$ photosynthetic photon flux density at the canopy height. Plants were acclimated to growth chamber conditions for 1 week before exposure to different temperature treatments.

Treatments AND EXPERIMENTAL DESIGN. Plants of both species were exposed to $35 / 30{ }^{\circ} \mathrm{C}$ (day/night) (high temperature) or $20 / 15^{\circ} \mathrm{C}$ (day/night) (control) for $35 \mathrm{~d}$. A total of four growth chambers was used in this study with two chambers being used simultaneously for each temperature treatment. Two pots for each species were placed inside each chamber. Four pots of plants (four replicates) for each species were relocated every week to different chambers so that plants exposed to each temperature were treated in four different chambers during the treatment period. The experiment consisted of two factors (temperature and species), which were arranged as a completely randomized block design. Plants were watered twice daily until free drainage occurred from the bottom of a pot to prevent water deficit during the treatment period.
Measurements. All the following measurements were made on plants in four pots (as four replicates) during the 14-h photoperiod. Turf quality was evaluated once a week based on color, density, and uniformity of the grass canopy using a 0 to 9 scale in which 9 represents fully green, dense turf canopy and 0 represents completely dead plants. Leaf photochemical efficiency of photosystem II (PSII) was also measured at a weekly interval with a fluorescence induction monitor (FIM 1500; Analytical Development Co. Ltd., Hoddesdon, U.K.) after a 30-min dark adaptation period. Photochemical efficiency was expressed as the ratio of $\mathrm{Fv} / \mathrm{Fm}$. [Fv/Fm $=(\mathrm{Fm}-$ $\mathrm{Fo} / \mathrm{Fm}$. Fo is the ground state value of fluorescence, and Fm is the maximum value of fluorescence.] The Fv/Fm value is $\approx 0.8$ in fully healthy plants. A lower value of $\mathrm{Fv} / \mathrm{Fm}$ indicates that a proportion of PSII reaction centers are damaged (Fracheboud and Leipner, 2003).

In addition, leaf tissues were sampled weekly for pigment quantification. Chlorophyll and carotenoid were extracted using dimethyl sulfoxide (DMSO). A $0.2 \mathrm{~g}$ of fresh leaves was incubated in $10 \mathrm{~mL}$ DMSO for $48 \mathrm{~h}$ in darkness. Original leaf extracts were diluted eight times and then the absorbance of the diluted extracts was determined using a spectrophotometer (Spectronic Genesys2; Spectronic Instruments, Rochester, N.Y.). Chlorophyll content was calculated based on the absorbance at 663 and $645 \mathrm{~nm}$, and carotenoid content was calculated based on the absorbance at 663, 645, and $470 \mathrm{~nm}$ using the formulas described by Arnon (1949).

Ethylene production of leaves was determined using a gas chromatograph (GC-8A; Shimadzu Scientific Instruments, Columbia, Md.) (Watkins and Frenkel, 1987). An airtight system was designed to collect ethylene gas evolved from leaves. Five to seven attached leaves were grouped and sealed inside a 10-mL syringe (Becton, Dickinson and Co., Franklin Lakes, N.J.) with a rubber stopper around the leaf base. Vacuum grease and Teflon tape were used to prevent leaks. Four groups of leaves from each pot were randomly selected and sealed in syringes as four subsamples. A $0.5-\mathrm{mL}$ gas sample from each syringe was taken through the rubber stopper every $2 \mathrm{~h}$ and injected into GC to determine ethylene concentration. Afterward, each group of leaves was excised and the fresh weight was measured. The average of hourly production of ethylene was calculated based on changes in ethylene concentration over time and a standard curve.

ABA and two forms of cytokinin (transZ/ZR and iPA) were quantified by an indirect competitive enzyme-linked immunosorbent assay. Extraction and quantification of hormones followed the method described by Setter et al. (2001) with some modifications (Wang and Huang, 2003). Briefly, samples were extracted in $80 \% \mathrm{v} / \mathrm{v}$ methanol and purified with reversephase $\mathrm{C}_{18}$ columns. Hydrophilic contaminants were washed out with $200 \mu \mathrm{L}$ of $20 \%$ solvent [20\% methanol, $80 \%$ aqueous triethylamine (TEA; $10 \mathrm{~mm}, \mathrm{pH} 3.5)]$. The cytokinin-containing fraction was eluted using $200 \mu \mathrm{L}$ of $30 \%$ solvent $(30 \%$ methanol, 70\% aqueous TEA) and the ABA-containing fraction was eluted using $150 \mu \mathrm{L}$ of $55 \%$ methanol.

Statistical analysis. Analysis of variance and correlation were based on the general linear model procedure of SAS (SAS Institute, Cary, N.C.). Effects of species, temperature, and their interactions were tested separately for each sampling date for all the parameters. Differences between treatment means for each species were separated by Fisher's protected least significant difference test at the $P=0.05$ level. 


\section{Results}

Changes in physioligical parameters associated with LEAF SENESCENCE AND HEAT TOLERANCE. Turf quality (TQ) of both species gradually declined over time at $35^{\circ} \mathrm{C}$ (Fig. 1). Turf quality for A. stolonifera declined to below the control level beginning at $14 \mathrm{~d}$ of treatment, whereas a significant decline in A. scabra was not observed until $35 \mathrm{~d}$. By $35 \mathrm{~d}$ of heat stress, turf quality decreased to $81 \%$ of the control for $A$. scabra and $56 \%$ of the control for A. stolonifera.

Under high temperature, plants of both species exhibited lower photochemical efficiency $(\mathrm{Fv} / \mathrm{Fm})$ than the control beginning at $14 \mathrm{~d}$ of treatment (Fig. 2). The decline in Fv/Fm became more dramatic with prolonging stress duration and more pronounced for A. stolonifera than A. scabra at $35^{\circ} \mathrm{C}$.

Leaf chlorophyll content for $A$. stolonifera decreased below the control level at $7 \mathrm{~d}$ of high temperature treatment, whereas that for A. scabra was maintained at the control level until $21 \mathrm{~d}$ of treatment (Fig. 3). Chlorophyll content in A. stolonifera exhibited greater extent of decline than that in A. scabra with prolonging duration of heat stress. Species variation and the
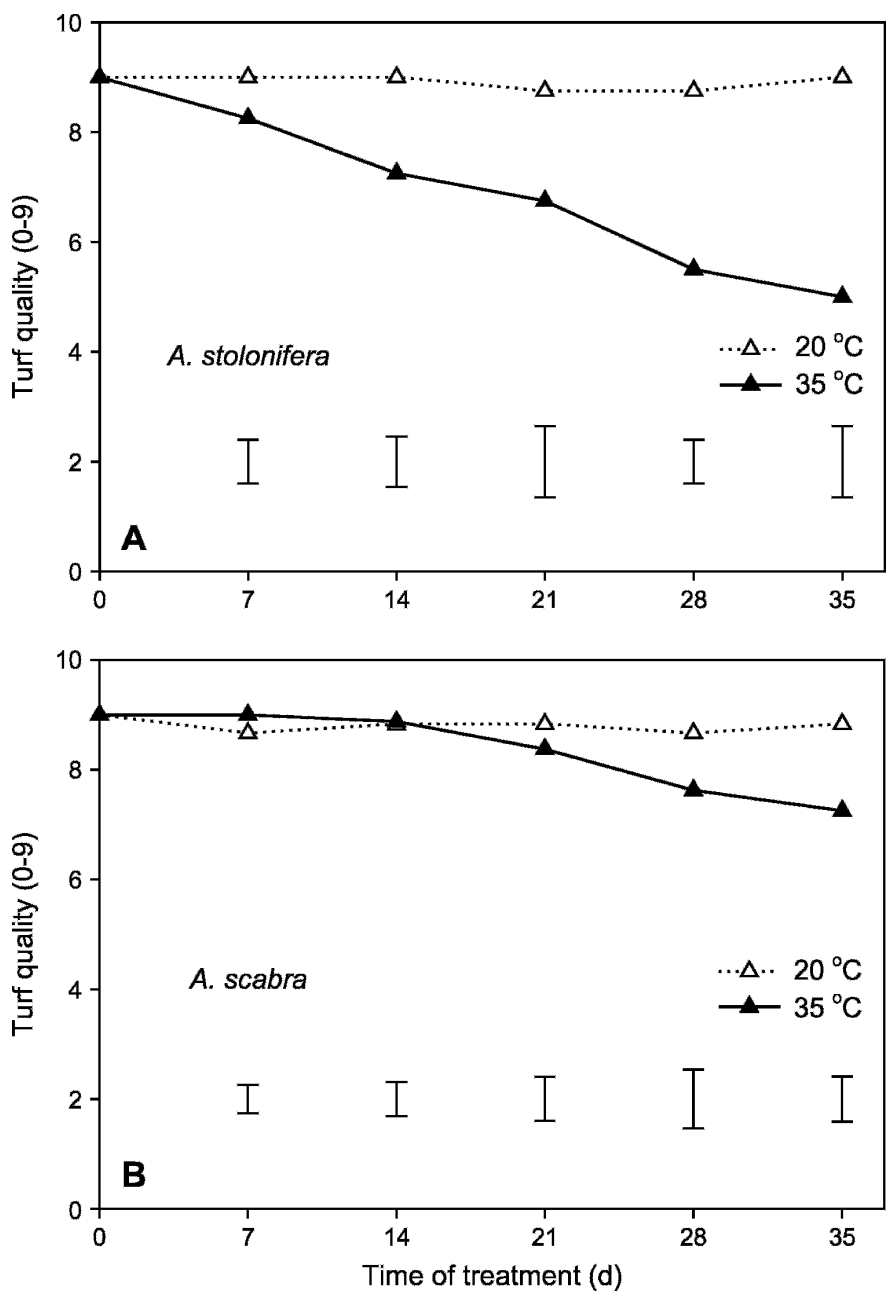

Fig. 1. Changes in turf quality over time at $20{ }^{\circ} \mathrm{C}$ (dotted lines and open symbols) or $35^{\circ} \mathrm{C}$ (solid lines and filled symbols) for (A) Agrostis stolonifera and (B) Agrostis scabra. Turf quality was evaluated using a 0 to 9 scale $(9=$ fully green, dense turf canopy; $0=$ completely dead plants) Vertical bars on the bottom indicate least significant differences $(P \leq 0.05)$ for temperature treatment comparison on a given day of treatment.

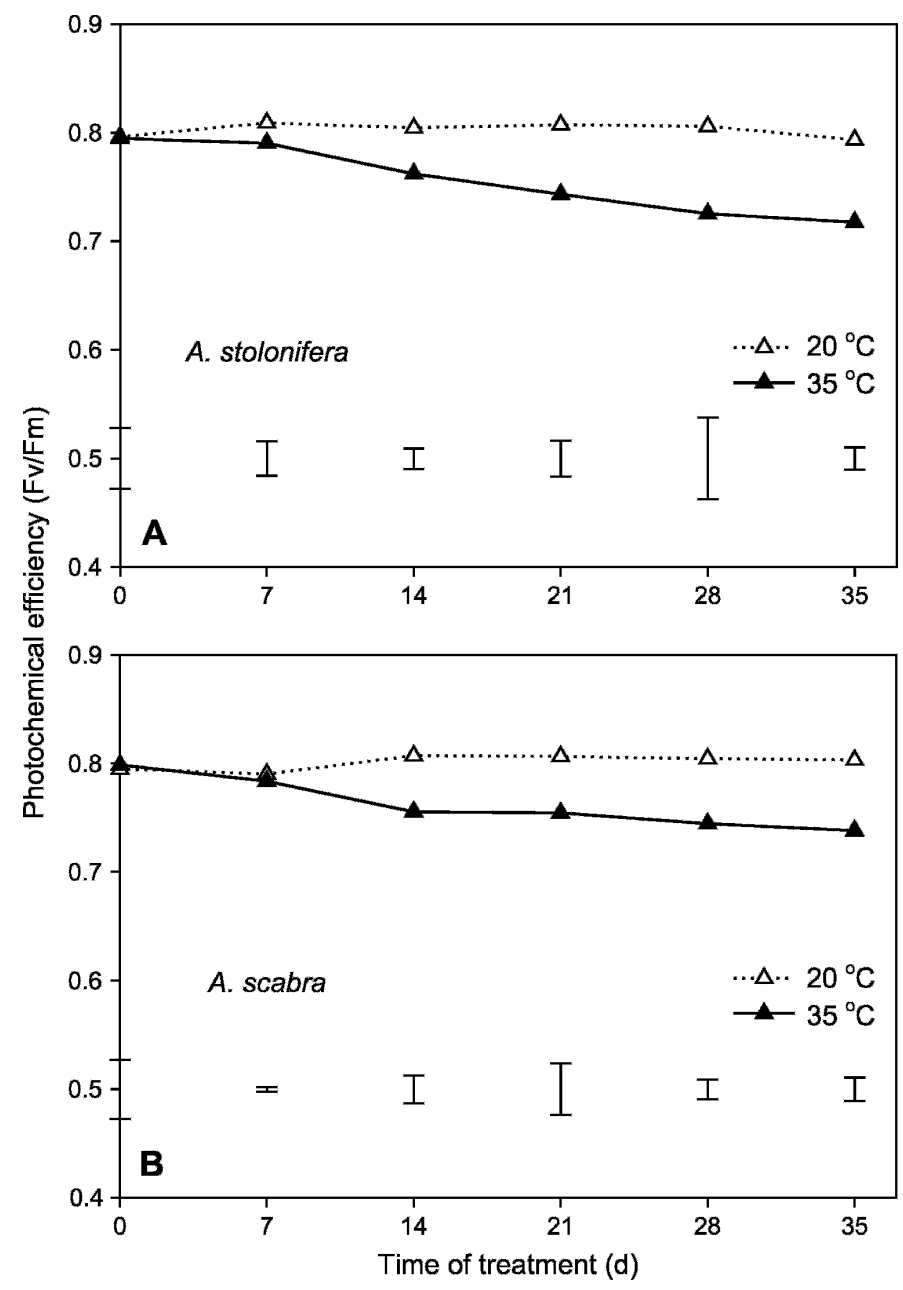

Fig. 2. Changes in leaf photochemical efficiency (measured as $\mathrm{Fv} / \mathrm{Fm}$ ratio) over time at $20^{\circ} \mathrm{C}$ (dotted lines and open symbols) or $35^{\circ} \mathrm{C}$ (solid lines and filled symbols) for (A) Agrostis stolonifera) and (B) Agrostis scabra. Vertical bars on the bottom indicate least significant differences $(P \leq 0.05)$ for temperature treatment comparison on a given day of treatment.

change in carotenoid content with stress duration followed a similar pattern to that of chlorophyll content (Fig. 4). In A. scabra plants exposed to high temperature, carotenoid content was maintained at the control level for $28 \mathrm{~d}$ before a significant decrease occurred. For A. stolonifera plants, the decrease started at $7 \mathrm{~d}$ and became significantly lower than the control after $14 \mathrm{~d}$. The decline in carotenoid contents for $A$. stolonifera was more pronounced than for $A$. scabra during the entire experimental period of the high temperature treatment.

Changes in ethylene, abSCISIC ACID, AND CYTOKININ CONTENT. Ethylene production rate increased with treatment duration in both species under high temperature except for A. scabra at $14 \mathrm{~d}$ of heat stress and was two to three times the initial level for both species at $35 \mathrm{~d}$ of treatment (Fig. 5). The timing of ethylene increase varied with species. In A. scabra, the rate of ethylene production at $35{ }^{\circ} \mathrm{C}$ did not increase significantly above the control level until $35 \mathrm{~d}$, whereas a significant increase occurred at 14 through $35 \mathrm{~d}$ of heat treatment for A. stolonifera.

At $35^{\circ} \mathrm{C}$, ABA content increased to the highest level at $14 \mathrm{~d}$ for A. stolonifera and at $21 \mathrm{~d}$ for A. scabra and declined 


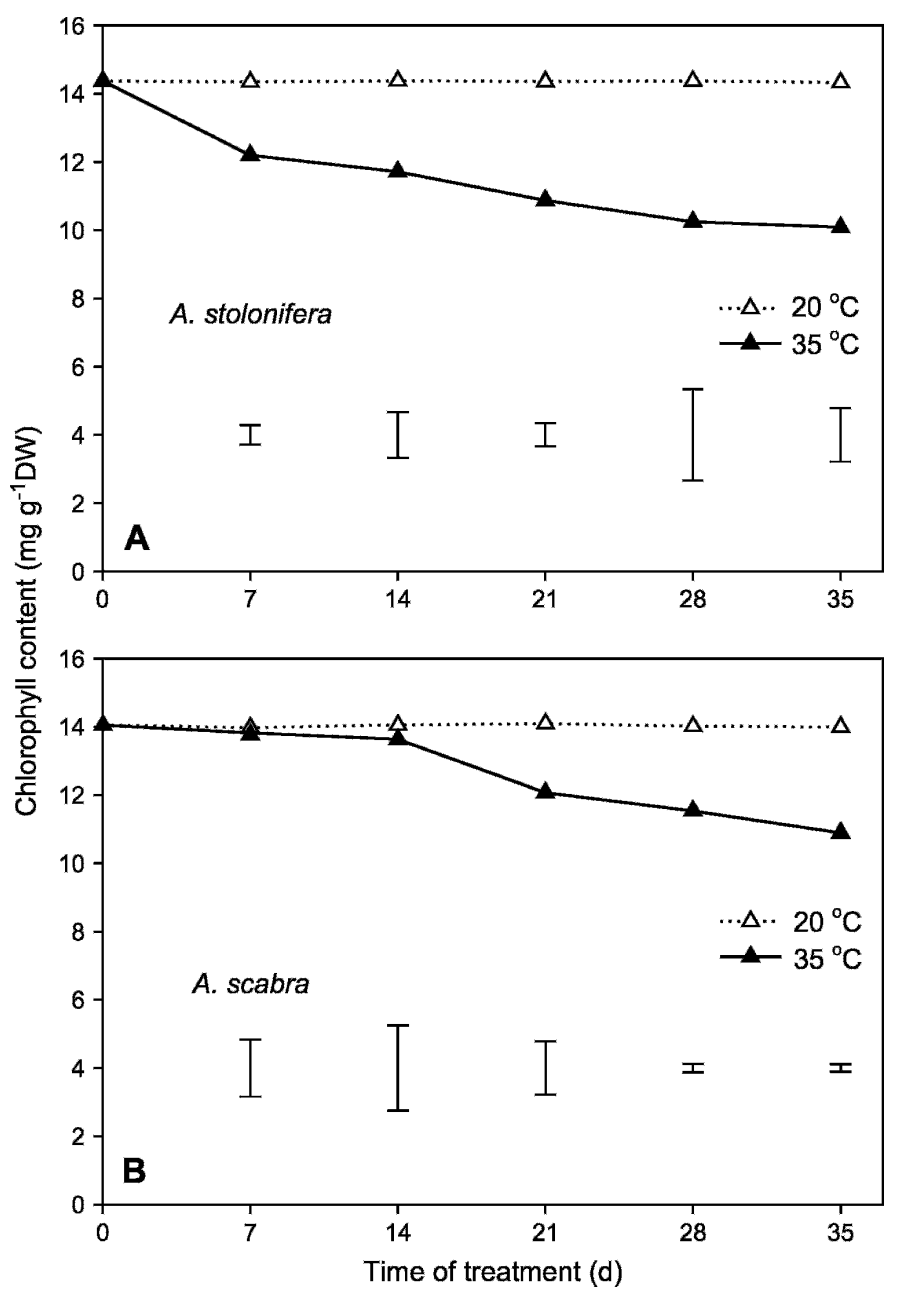

Fig. 3. Changes in leaf chlorophyll content $\left(\mathrm{mg} \cdot \mathrm{g}^{-1} \mathrm{DW}\right)$ over time at $20{ }^{\circ} \mathrm{C}$ (dotted lines and open symbols) or $35^{\circ} \mathrm{C}$ (solid lines and filled symbols) for (A) Agrostis stolonifera and (B) Agrostis scabra. Vertical bars on the bottom indicate least significant differences $(P \leq 0.05)$ for temperature treatment comparison on a given day of treatment.

thereafter. However, ABA content was significantly higher than the control level after only $7 \mathrm{~d}$ of treatment for A. stolonifera and after $21 \mathrm{~d}$ for $A$. scabra (Fig. 6). In addition, the peak values of ABA varied with species, which was $77.4 \mathrm{pmol} \cdot \mathrm{g}^{-1}$ fresh weight (FW) for A. stolonifera (5.9 times that of the control) and $64.6 \mathrm{pmol} \cdot \mathrm{g}^{-1} \mathrm{FW}$ for $A$. scabra, which was equal to 4.0 times that of the control value.

The content of both forms of cytokinins declined with the progression of heat stress for both species (Figs. 7 and 8). For iPA content, the decrease in $A$. scabra became significant after $14 \mathrm{~d}$, whereas in A. stolonifera, it became significant after only $7 \mathrm{~d}$ (Fig. 7). At $35 \mathrm{~d}$ of heat stress, the content of iPA for A. scabra was reduced to $30 \%$ of the initial level, whereas that in A. stolonifera was reduced to $22 \%$. The decrease in Z/ZR content became significant after $14 \mathrm{~d}$ of heat stress for $A$. scabra and $7 \mathrm{~d}$ for $A$. stolonifera. At the end of the treatment period, Z/ZR cytokinin declined by $65 \%$ for $A$. stolonifera and by $50 \%$ for A. scabra (Fig. 8).

Correlation Between hormones and SENESCENCE PARAMETERS. In general, ethylene and ABA contents were negatively correlated to $\mathrm{TQ}$, leaf $\mathrm{Fv} / \mathrm{Fm}$, chlorophyll, and carotenoid contents, whereas both forms of cytokinin contents

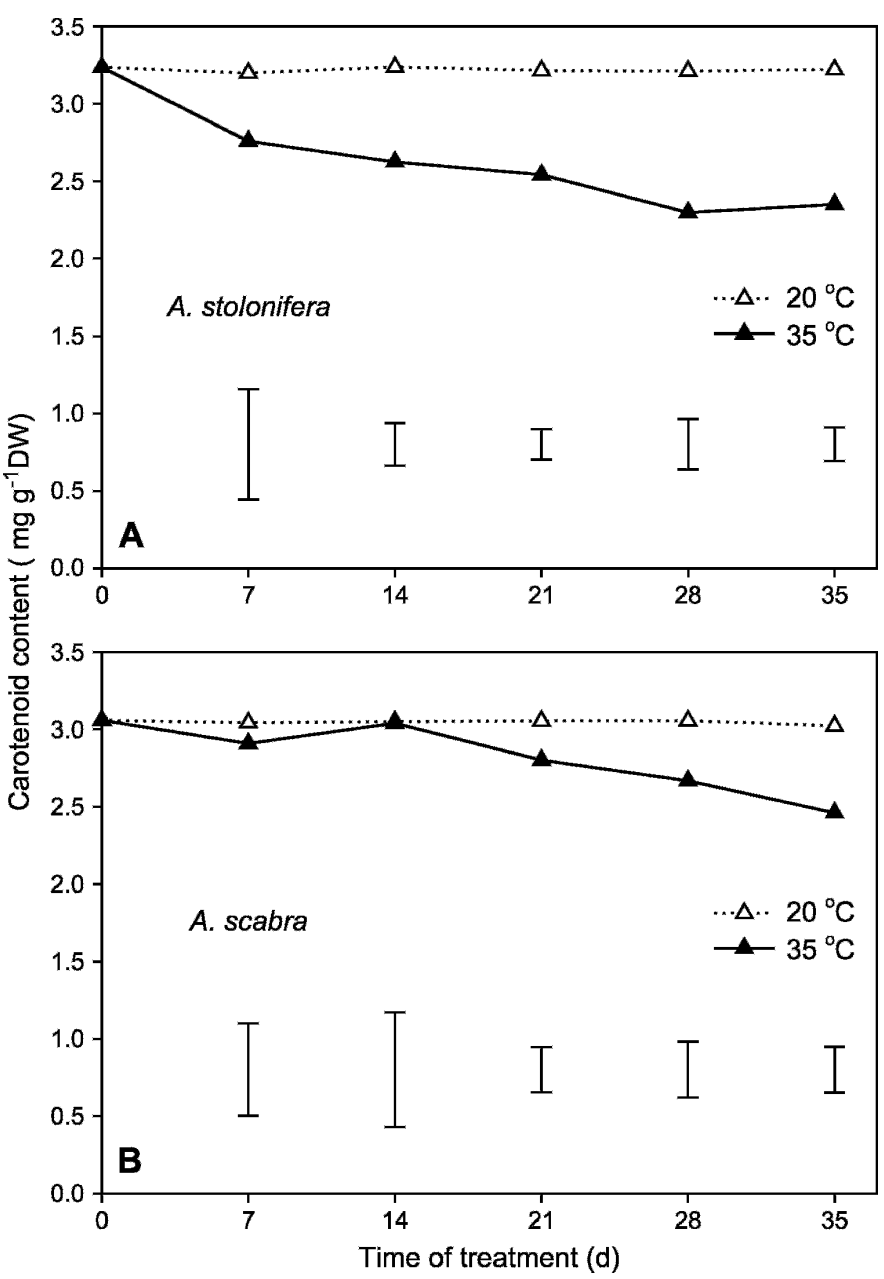

Fig. 4. Changes in carotenoid content $\left(\mathrm{mg} \cdot \mathrm{g}^{-1} \mathrm{DW}\right.$ ) over time at $20^{\circ} \mathrm{C}$ (dotted lines and open symbols) or $35^{\circ} \mathrm{C}$ (solid lines and filled symbols) for (A) Agrostis stolonifera and (B) Agrostis scabra. Vertical bars on the bottom indicate least significant differences $(P \leq 0.05)$ for temperature treatment comparison on a given day of treatment.

had positive correlations with these parameters for both species (Tables 1 and 2). For A. stolonifera, there were significant correlations of ethylene and cytokinins with all senescence parameters with higher correlation coefficients for ethylene (ranging from -0.90 to -0.96 ) than cytokinins (ranging from 0.72 to 0.94 ) (Table 1). No significant correlations were detected between ABA and physiological parameters. For A. scabra, the correlation coefficients between all three hormones and senescence parameters were highly significant, which ranged from $-0.51(\mathrm{Fv} / \mathrm{Fm})$ to -0.83 (carotenoid) for ethylene, $-0.51(\mathrm{Fv} / \mathrm{Fm})$ to -0.75 (chlorophyll) for ABA, 0.60 (TQ) to $0.79(\mathrm{Fv} / \mathrm{Fm})$ for iPA and $0.63(\mathrm{TQ})$ to $0.89(\mathrm{Fv} / \mathrm{Fm})$ for Z/ZR (Table 2).

\section{Discussion}

The decline of turfgrass quality under heat stress was observed 3 weeks earlier in A. stolonifera compared with $A$. scabra. Changes in chlorophyll and carotenoid exhibited consistent differences in the timing and severity of leaf senescence induced by heat treatment between two species. Both chlorophyll and carotenoid contents were maintained at 


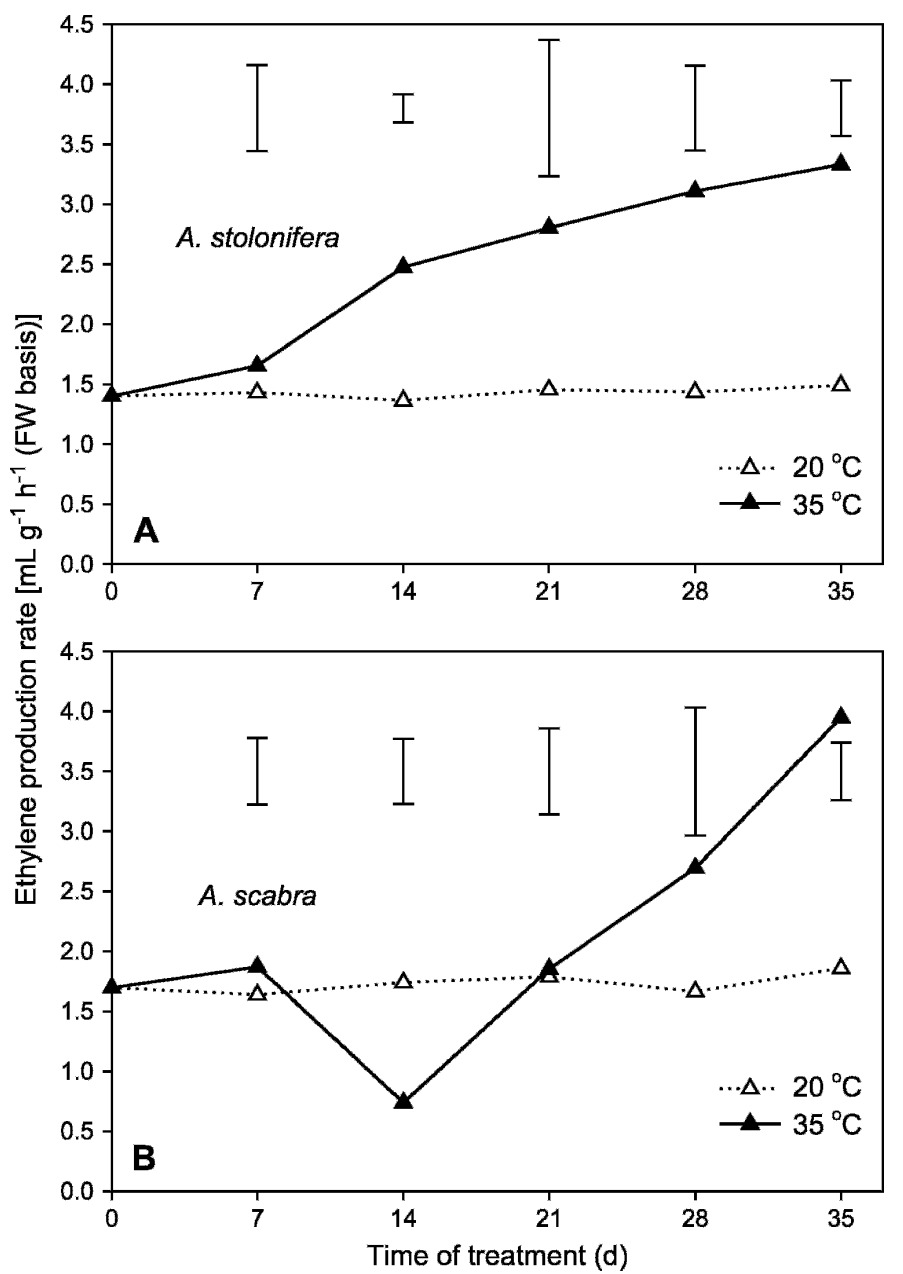

Fig. 5. Changes in leaf ethylene production rate $\left[\mathrm{nL} \cdot \mathrm{g}^{-1} \cdot \mathrm{h}^{-1}\right.$ (FW basis)] over time at $20^{\circ} \mathrm{C}$ (dotted lines and open symbols) or $35^{\circ} \mathrm{C}$ (solid lines and filled symbols) for (A) Agrostis stolonifera and (B) Agrostis scabra. Vertical bars on the bottom (A) or top (B) indicate least significant differences $(P \leq 0.05)$ for temperature treatment comparison on a given day of treatment.

the control level for $\approx 14 \mathrm{~d}$ in $A$. scabra without any significant decrease until 21 and $28 \mathrm{~d}$, respectively. The decline in TQ, chlorophyll, and carotenoid content was less severe for A. scabra than A. stolonifera. These results demonstrated that heat-tolerant $A$. scabra exhibited delayed and less severe leaf senescence under heat stress. Previous studies on root response to high temperatures for these two species also found that A. scabra exhibited higher tolerance to high soil temperature than A. stolonifera with smaller decreases in root growth rate, cell membrane stability, maximum root length, and nitrate uptake (Lyons et al., 2006; Rachmilevitch et al., 2006).

Ethylene production has been considered an important factor contributing to natural senescence or abscission of leaves and reproductive organs (Yang and Hoffman, 1984). Enhanced ethylene production has also been associated with reduced growth and accelerated senescence in response to environmental stresses (Balota et al., 2004; Huberman et al., 2004). Limited literature is available in the association of ethylene production with heat tolerance. In our studies, ethylene production rate of both bentgrass species increased significantly under heat stress when there was a $20 \%$ decline in chlorophyll content (Fig. 3). One study in winter wheat (T. aestivum) reported that the

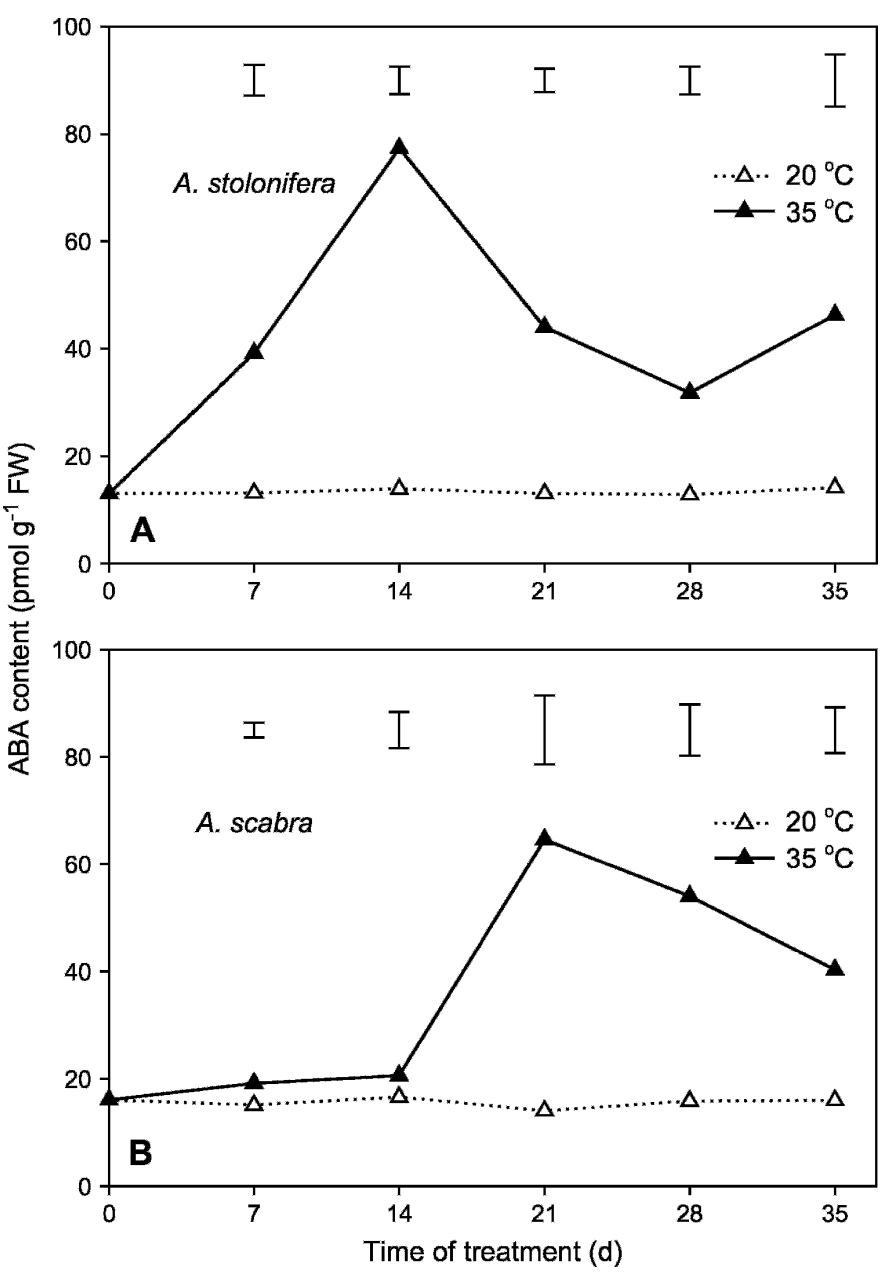

Fig. 6. Changes in leaf abscisic acid content (pmol.g ${ }^{-1} \mathrm{FW}$ ) over time at $20{ }^{\circ} \mathrm{C}$ (dotted lines and open symbols) or $35^{\circ} \mathrm{C}$ (solid lines and filled symbols) for (A) Agrostis stolonifera and (B) Agrostis scabra. Vertical bars on the top indicate least significant differences $(P \leq 0.05)$ for temperature treatment comparison on a given day of treatment.

stress-resistant 'Dropia' produced significantly greater ethylene than stress-susceptible 'Delia' under high temperature $\left(38^{\circ} \mathrm{C}\right)$ (Balota et al., 2004). We did not observe significant differences in ethylene accumulation between the two bentgrass species tested. Ethylene production increased to a similar extent for both species after $35 \mathrm{~d}$ of heat treatment. However, the initiation of the increase was $14 \mathrm{~d}$ later in $A$. scabra than in A. stolonifera under stress conditions. In addition, a significant decrease in ethylene content was observed for $A$. scabra at $14 \mathrm{~d}$ of heat stress, which may be part of the defense mechanisms of this species against heat stress. The delay of ethylene accumulation in A. scabra was consistent with the delay of leaf senescence as manifested by TQ and chlorophyll and carotenoid contents.

The accumulation of ABA in response to heat shock and other stresses has been reported in several plant species, including maize (Zea mays L.), durum wheat (Triticum durum Desf.), and pea (Pisum sativum L.) (Musatenko et al., 2003; Shakirova et al., 1995; Veselov et al., 1998). In our study, ABA accumulation occurred at $35^{\circ} \mathrm{C}$ for both species, exhibiting a peak at 14 and $21 \mathrm{~d}$ for A. stolonifera and A. scabra, respectively. Similar results have recently been reported for 


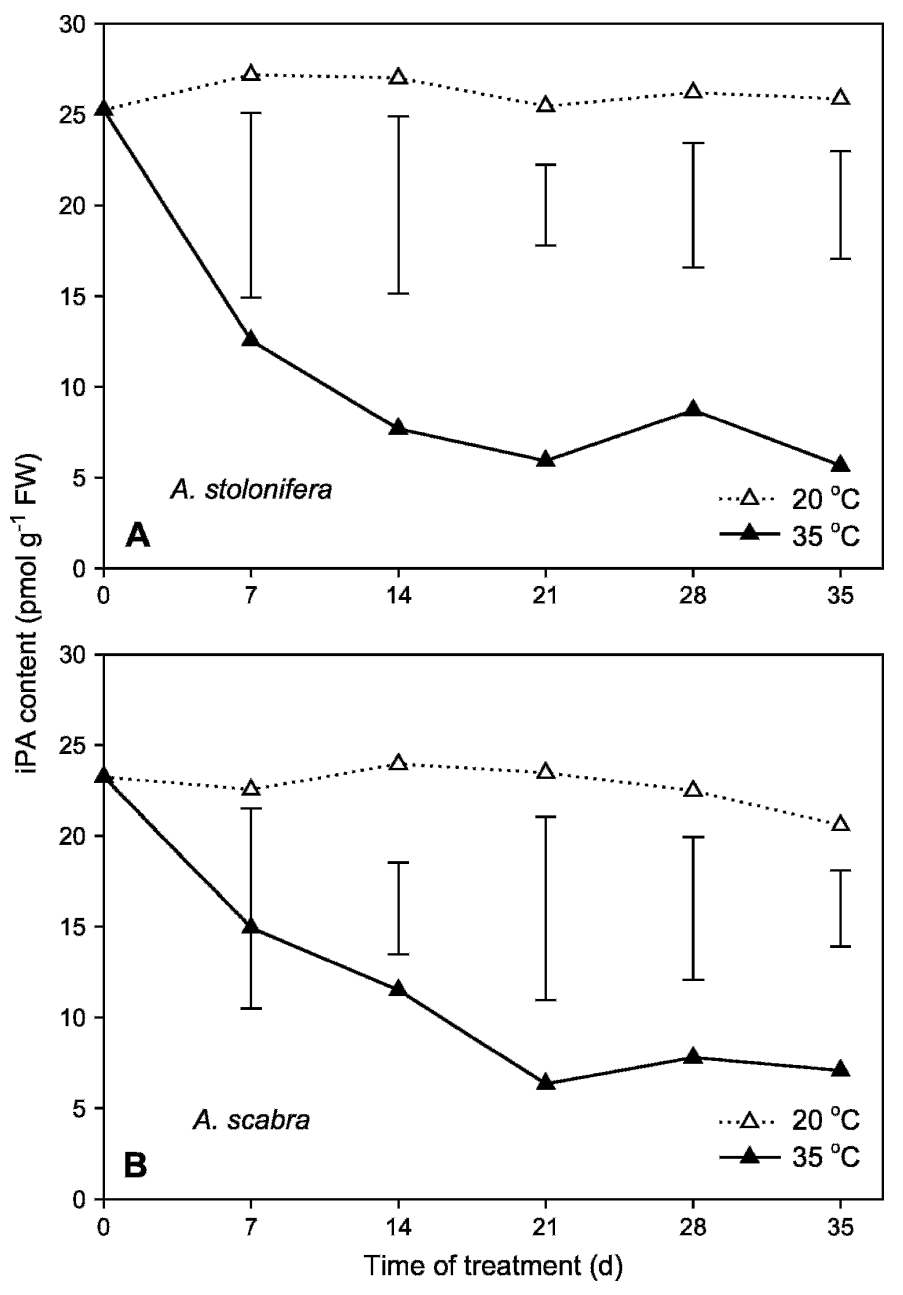

Fig. 7. Changes in isopentenyl adenosine (iPA) content (pmol. $\left.{ }^{-1} \mathrm{FW}\right)$ over time at $20^{\circ} \mathrm{C}$ (dotted lines and open symbols) or $35^{\circ} \mathrm{C}$ (solid lines and filled symbols) for (A) Agrostis stolonifera and (B) Agrostis scabra. Vertical bars in the middle indicate least significant differences $(P \leq 0.05)$ for temperature treatment comparison on a given day of treatment.

grape (Vitis vinifera L. cv. Jinoxiu), in which ABA content drastically increased within $1 \mathrm{~h}$ after heat treatments $\left(38{ }^{\circ} \mathrm{C}\right)$ (Wang et al., 2005). However, the increase in A. scabra was delayed for $14 \mathrm{~d}$ and the maximum accumulation at the peak was smaller compared with $A$. stolonifera. These results suggested that $A$. scabra could maintain its ABA content for a longer period of time and exhibit a less pronounced increase when exposed to prolonged heat treatment, which could possibly be associated with less stress injury and better heat tolerance.

Both Z/ZR and iPA production consistently decreased under heat stress as demonstrated in both bentgrass species in our study and many nonturf plant species in various other studies. One potential explanation for cytokinin reduction in shoots is the result of inhibition of cytokinin transport from roots to shoots under elevated temperatures, because cytokinins are primarily produced in roots. This perspective is supported by a study imposed in wheat, which reported that the content of cytokinins decreased in shoots and accumulated in roots simultaneously as a result of temperature increase (Farkhutdinov et al., 1997). Additionally, the decline of endogenous cytokinins in senescing tissues may be the result of a decrease in

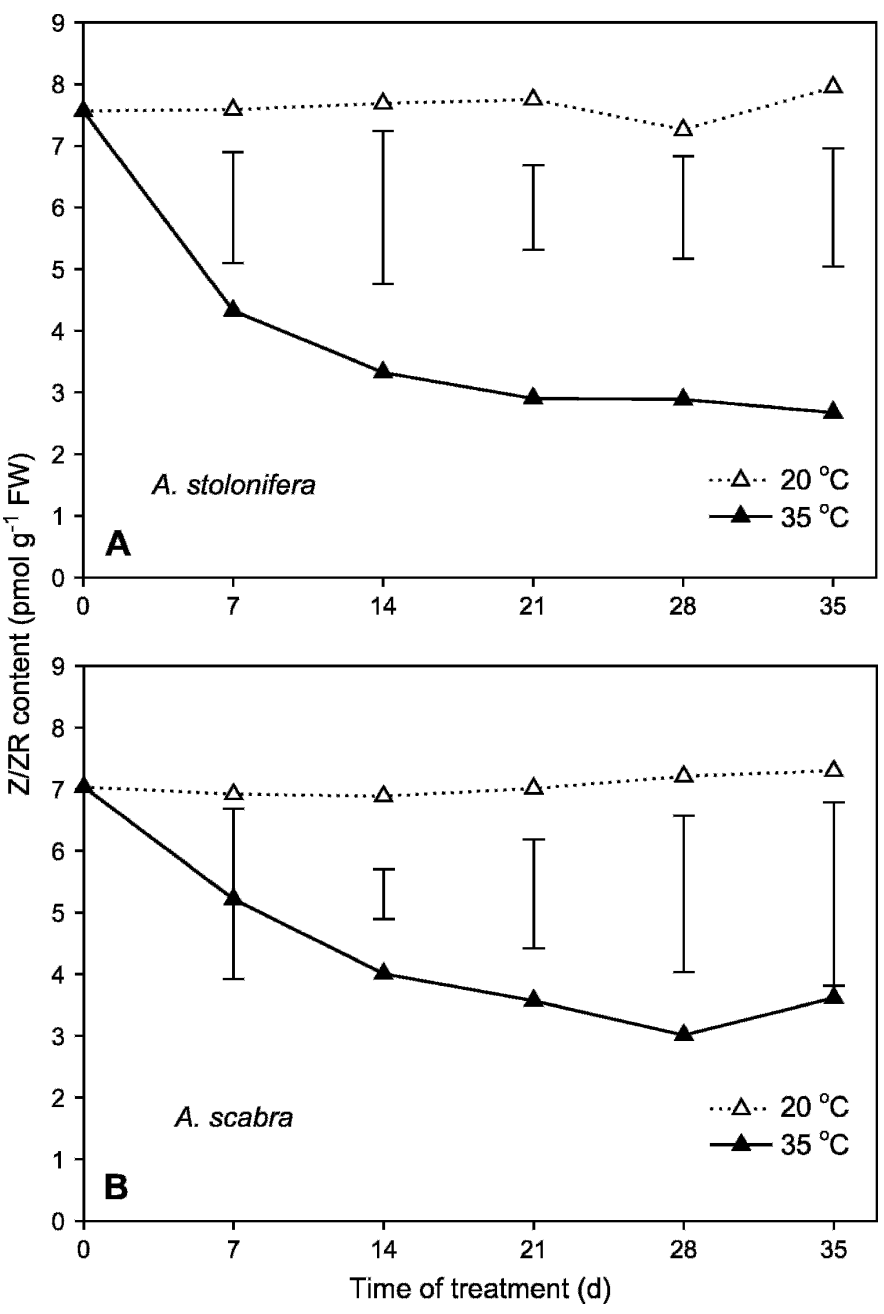

Fig. 8. Changes in transzeatin/zeatin riboside $(\mathrm{Z} / \mathrm{ZR})$ content $\left(\mathrm{pmol} \cdot \mathrm{g}^{-1} \mathrm{FW}\right)$ over time at $20^{\circ} \mathrm{C}$ (dotted lines and open symbols) or $35^{\circ} \mathrm{C}$ (solid lines and filled symbols) for (A) Agrostis stolonifera and (B) Agrostis scabra. Vertical bars on the bottom indicate least significant differences $(P \leq 0.05)$ for temperature treatment comparison on a given day of treatment.

Table 1. Correlations of ethylene, abscisic acid (ABA), isopentenyl adenosine (iPA), and transzeatin/zeatin riboside (Z/ZR) with senescence parameters (turf quality, Fv/Fm, chlorophyll, and carotenoid contents) under heat stress $\left(35^{\circ} \mathrm{C}\right)$ for Agrostis stolonifera ${ }^{\mathrm{z}}$.

\begin{tabular}{lllll}
\hline & Ethylene & ABA & iPA & Z/ZR \\
\hline Turf quality & $-0.90^{* *}$ & -0.25 & $0.72^{* *}$ & $0.79^{* *}$ \\
Fv/Fm & $-0.92^{* *}$ & -0.29 & $0.73^{* *}$ & $0.74 * *$ \\
Chlorophyll & $-0.96^{* *}$ & -0.42 & $0.88^{* *}$ & $0.94 * *$ \\
Carotenoid & $-0.90^{* *}$ & -0.45 & $0.87 * *$ & $0.93 * *$
\end{tabular}

${ }^{\mathrm{z}}$ The significance of correlation coefficients was tested at $P \leq 0.05(*)$ and $P \leq 0.01(* *)$.

biosynthesis or an increase in catabolism (Nooden and Leopoid, 1988). It would be necessary to examine specific changes in cytokinin synthesis, degradation, and mobilization to reveal the mode of actions of cytokinin in heat tolerance of plants, including turfgrass. In terms of species variation, the decreases of both forms of cytokinins were delayed for $7 \mathrm{~d}$ and less severe after $35 \mathrm{~d}$ of heat stress in A. scabra than in A. stolonifera, suggesting that maintenance of a higher level of endogenous 
Table 2. Correlations of ethylene, abscisic acid (ABA), isopentenyl adenosine (iPA), and transzeatin/zeatin riboside (Z/ZR) with senescence parameters (turf quality, Fv/Fm, chlorophyll, and carotenoid contents) under heat stress $\left(35^{\circ} \mathrm{C}\right)$ for Agrostis scabra $^{\mathrm{z}}$.

\begin{tabular}{lllcc}
\hline & Ethylene & ABA & iPA & Z/ZR \\
\hline Turf quality & $-0.81^{* *}$ & $-0.53^{*}$ & $0.60^{* *}$ & $0.63^{* *}$ \\
Fv/Fm & $-0.51^{*}$ & $-0.51^{*}$ & $0.79^{* *}$ & $0.89^{* *}$ \\
Chlorophyll & $-0.77^{* *}$ & $-0.75^{* *}$ & $0.77^{* *}$ & $0.77^{* *}$ \\
Carotenoid & $-0.83^{* *}$ & $-0.56^{*}$ & $0.67 * *$ & $0.68^{* *}$ \\
\hline
\end{tabular}

${ }^{\mathrm{z}}$ The significance of correlation coefficients was tested at $P \leq 0.05\left(^{*}\right)$ and $P \leq 0.01(* *)$.

cytokinin for a longer period of time may contribute to better heat tolerance.

Data from correlation analysis demonstrated that endogenous ethylene and ABA production were negatively correlated and cytokinin production was positively correlated with heatinduced leaf senescence; however, the correlation with ABA was not significant for $A$. stolonifera. Thus, approaches that can increase endogenous cytokinin levels or suppress ethylene production may lead to improved heat tolerance and delayed foliar senescence. Exogenous application of cytokinin, or its derivatives, may be one possible method. Liu et al. (2002) reported that applications of 1 and $10 \mathrm{~mm} Z \mathrm{ZR}$ to the root zone of creeping bentgrass increased cytokinin content in leaves and roots and mitigated heat stress injury in both shoots and roots. Endogenous cytokinin levels may also be increased by transgenic approaches. Teplova et al. (2000) transformed tobacco plants with the ipt gene that codes for isopentenyltransferase, which was subsequently expressed after a heat shock treatment. Elevated temperature resulted in a decrease in the transpiration of wild-type plants, whereas the transpiration rate was maintained at high levels in transgenic plants. Conversely, because ethylene production was negatively correlated with heatinduced senescence, delayed leaf senescence may also be achieved by transgenic approaches that can perturb endogenous ethylene-response signal transduction pathways (Suzuki et al., 2005). However, blocking ethylene production may be detrimental to heat tolerance. Larkindale and Knight (2002) reported that ethylene was necessary in protection against heat-induced oxidative damage in Arabidopsis thaliana (L.) Heynh. because the ethylene-insensitive mutant etr- 1 showed increased susceptibility to heat. These studies indicate the complex interaction of hormones and stress tolerance.

In summary, heat-tolerant A. scabra exhibited delayed and less severe leaf senescence during heat stress compared with heat-sensitive $A$. stolonifera. The increases in ethylene and ABA, and decreases in cytokinins, could contribute to heatinduced leaf senescence and differences in heat tolerance between the two bentgrass species. Ethylene and cytokinins were more closely correlated to physiological parameters associated with leaf senescence and heat tolerance than ABA, especially for heat-sensitive $A$. stolonifera. This suggested that approaches that can suppress endogenous ethylene, or increase cytokinin levels, may be used to delay foliar senescence and ultimately improve heat tolerance.

\section{Literature Cited}

Adedipe, N.O. 1971. Effects of benzyladenine on photosynthesis, growth and senescence of bean plant. Physiol. Plant. 25:151-153.
Arnon, D. 1949. Copper enzymes in isolated chloroplasts. Plant Physiol. 24:1-15.

Balota, M., S. Cristescu, W.A. Payne, S.T.L. Hekkert, L.J.J. Laarhoven, and F.J.M. Harren. 2004. Ethylene production of two wheat cultivars exposed to desiccation, heat, and paraquat-induced oxidation. Crop Sci. 44:812-818.

Becker, W. and K. Apel. 1993. Differences in gene expression between natural and artifically induced leaf senescence. Planta 189:74-79.

Chang, H.S., M.L. Jones, G.M. Banowetz, and D.G. Clark. 2003. Overproduction of cytokinins in petunia flowers transformed with P-SAG12-IPT delays corolla senescence and decreases sensitivity to ethylene. Plant Physiol. 132:2174-2183.

Farkhutdinov, R.G., S.U. Veselov, and G.R. Kudoyarova. 1997. Influence of temperature increase on evapotranspiration rate and cytokinin content in wheat seedlings. Biol. Plant. 39:289-291.

Fracheboud, Y. and J. Leipner. 2003. Using chlorophyll fluorescence to study photosynthesis, p. 125-150. In: J.R. DeEll and P.M.A. Toivonen (eds.). Practical applications of chlorophyll fluorescence in plant biology. Kluwer Academic Publishers, Dordrecht, The Netherlands.

Grbic, V. and A.B. Bleecker. 1995. Ethylene regulates the timing of leaf senescence in arabidopsis. Plant J. 8:595-602.

Huang, B. and H. Gao. 2000. Growth and carbohydrate metabolism of creeping bentgrass cultivars in response to increasing temperatures. Crop Sci. 40:1115-1120.

Huang, B., X. Liu, and J.D. Fry. 1998. Shoot physiological responses of two bentgrass cultivars to high temperature and poor soil aeration. Crop Sci. 38:1219-1224.

Huberman, M., J. Riov, B. Aloni, and R. Goren. 2004. Role of ethylene biosynthesis and auxin content and transport in high temperatureinduced abscission of pepper reproductive organs. J. Plant Growth Regulat. 16:129-135.

John, I., R. Drake, A. Farrell, W. Cooper, P. Lee, P. Horton, and D. Grierson. 1995. Delayed leaf senescence in ethylene-deficient ACC-oxidase antisense tomato plants - molecular and physiological analysis. Plant J. 7:483-490.

Jordi, W., A. Schapendonk, E. Davelaar, G.M. Stoopen, C.S. Pot, R. De Visser, J.A. Van Rhijn, S. Gan, and R.M. Amasino. 2000. Increased cytokinin levels in transgenic P-SAG12-IPT tobacco plants have large direct and indirect effects on leaf senescence, photosynthesis and N partitioning. Plant Cell Environ. 23:279-289.

Larkindale, J. and M.R. Knight. 2002. Protection against heat stressinduced oxidative damage in arabidopsis involves calcium, abscisic acid, ethylene, and salicylic acid. Plant Physiol. 128:682-695.

Liu, X., B. Huang, and G. Banowetz. 2002. Cytokinin effects on creeping bentgrass responses to heat stress: I. Shoot and root growth. Crop Sci. 42:457-465.

Lyons, E., J. Pote, M. DaCosta, and B. Huang. 2006. Whole-plant carbon relations and root respiration associated with root tolerance to high soil temperature for Agrostis grasses. Environ. Exp. Bot. 59:307-313. Musatenko, L.I., N.P. Vedenicheva, V.A. Vasyuk, and V.N. Generalova. 2003. Phytohormones in seedlings of maize hybrids differing in their tolerance to high temperature. Russ. J. Plant Physiol. 50:499-504.

Nooden, L.D. and A.C. Leopoid. 1988. Senescence and aging in plants. Academic Press, San Diego.

Rachmilevitch, S., H. Lambers, and B.R. Huang. 2006. Root respiratory characteristics associated with plant adaptation to high soil temperature for geothermal and turf-type Agrostis species. J. Expt. Bot. 57:623-631.

Setter, T.L., B.A. Flannigan, and J. Melkonian. 2001. Loss of kernel set due to water deficit and shade in maize: Carbohydrate supplies, abscisic acid, and cytokinins. Crop Sci. 41:1530-1540.

Shakirova, F.M., M.V. Bezrukova, and I.F. Shayakhmetov. 1995. The effect of heat-shock on the accumulation of ABA and lectin in wheat callus cells. Russ. J. Plant Physiol. 42:621-623.

Stout, R.G. and T.S. Al-Niemi. 2002. Heat-tolerant flowering plants of active geothermal areas in Yellowstone National Park. Ann. Bot. (Lond.) 90:259-267. 
Suzuki, N., L. Rizhsky, H.J. Liang, J. Shuman, V. Shulaev, and R. Mittler. 2005. Enhanced tolerance to environmental stress in transgenic plants expressing the transcriptional coactivator multiprotein bridging factor 1c. Plant Physiol. 139:1313-1322.

Teplova, I.R., R.G. Farkhutdinov, A.N. Mitrichenko, I.I. Ivanov, S.Y. Veselov, R.L. Valcke, and G.R. Kudoyarova. 2000. Response of tobacco plants transformed with the ipt gene to elevated temperature. Russ. J. Plant Physiol. 47:367-369.

Tercek, M.T., D.P. Hauber, and S.P. Darwin. 2003. Genetic and historical relationships among geothermally adapted Agrostis (bentgrass) of North America and Kamchatka: Evidence for a previously unrecognized, thermally adapted taxon. Amer. J. Bot. 90: 1306-1312.

Thomas, H. and J.L. Stoddart. 1980. Leaf senescence. Ann. Rev. Plant Physiol. 31:83-111.

Veselov, A.P., V.P. Lobov, and L.N. Olyunina. 1998. Phytohormones during heat shock and recovery. Russ. J. Plant Physiol. 45:611-616.

Wang, L.J., W.D. Huang, Y.P. Liu, and J.C. Zhan. 2005. Changes in salicylic and abscisic acid contents during heat treatment and their effect on thermotolerance of grape plants. Russ. J. Plant Physiol. 52:516-520.
Wang, Z. and B. Huang. 2003. Genotypic variation in abscisic acid accumulation, water relations, and gas exchange for Kentucky bluegrass exposed to drought stress. J. Amer. Soc. Hort. Sci. 128:349-355.

Watkins, C.B. and C. Frenkel. 1987. Inhibition of pear fruit ripening by mannose. Plant Physiol. 85:56-61.

Xiong, L.M., K.S. Schumaker, and J.K. Zhu. 2002. Cell signaling during cold, drought, and salt stress. Plant Cell 14:S165-S183.

Xu, Q.A., A.Q. Paulsen, J.A. Guikema, and G.M. Paulsen. 1995. Functional and ultrastructural injury to photosynthesis in wheat by high temperature during maturation. Environ. Exp. Bot. 35:43-54.

Yang, J.C., J.H. Zhang, Z.Q. Wang, Q.S. Zhu, and L.J. Liu. 2002. Abscisic acid and cytokinins in the root exudates and leaves and their relationship to senescence and remobilization of carbon reserves in rice subjected to water stress during grain filling. Planta 215: 645-652.

Yang, S.F. and N.E. Hoffman. 1984. Ethylene biosynthesis and its regulation in higher plants. Ann. Rev. Plant Physiol. 35:155-189.

Yeh, D.M. and P.Y. Hsu. 2004. Heat tolerance in English ivy as measured by an electrolyte leakage technique. J. Hort. Sci. Biotechnol. 79:298-302. 